\title{
AS DUAS TEORIAS ARQUIVÍSTICAS SEGUNDO JOHN ROBERTS: UMA CONTRIBUIÇÃO AOS FUNDAMENTOS DO CAMPO
}

\author{
LAS DOS TEORÍAS DE ARCHIVO POR JOHN \\ ROBERTS: UNA CONTRIBUCIÓN A LOS \\ FUNDAMENTOS DEL CAMPO
}

\author{
Shirley Carvalhêdo Franco* \\ Icléia Thiesen** \\ Georgete Medleg Rodrigues***
}

\begin{abstract}
RESUMO:
Introdução: O conceito de fundo, bem como o de princípio da proveniência, são dois fundamentos da teoria arquivística. Entretanto, frequentemente surge a questão se é pertinente o estudo do conceito de fundo e o de princípio da proveniência, se estes realmente diferenciam os documentos de arquivo de outros e se têm o poder de elevar o estudo dos arquivos ao estatuto de ciência. Objetivo: Fazer uma revisão da literatura científica da área de Arquivologia sobre os fundamentos arquivísticos, apresentando os principais pontos abordados por autores da área de Arquivologia no que diz respeito ao princípio da proveniência e ao conceito de fundo e os problemas apontados por alguns desses autores, com destaque para o pensamento do arquivista norte-americano John Roberts. Metodologia: Análise de vinte e três trabalhos científicos, dentre livros e artigos, compreendendo o período entre 1922 a 2015, com a elaboração de um quadro sintético organizado por ano, autor, título e pontos de destaque da obra, país de origem do autor, separando-se os autores considerados clássicos na área e os contemporâneos. Formulação de três questões para um dos autores, enviadas por correio eletrônico. Resultados e conclusões: Enquanto os autores clássicos reafirmam a validade dos fundamentos, contribuindo para 0 constructo da disciplina, os autores contemporâneos, a partir de 1960, passaram a tecer críticas sobretudo ao conceito de fundo e a propor reformulações e complementações ao princípio da proveniência, como, por exemplo, "a noção de ramificação". Compondo o grupo dos autores contemporâneos destacou-se John Roberts, professor norte-americano de Arquivologia, que, em um conjunto de três textos, tece severas críticas a alguns elementos consagrados da teoria arquivística. Ao responder as questões, John Roberts expôs a gênese de seus questionamentos e a existência, para ele, de duas teorias arquivísticas: uma, dita "necessária", e a outra, "supérflua".
\end{abstract}

*Doutora em Ciência da Informação. Professora da Faculdade de Ciência da Informação da Universidade de Brasília (UnB). shirley.carvalhedo@gmail.com

**Doutora em Ciência da Informação. Professora do PPGCI Universidade Federal do Estado do Rio de Janeiro (UniRio) icleiathiesen@gmail.com

***Doutora em História pela Université de Paris (Paris IV- Sorbonne). Professora do PPGCI da Universidade de Brasília (UnB). medleg.georgete@gmail.com 
Shirley Carvalhêdo Franco, Icléia Thiesen, Georgete Medleg Rodrigues

As duas teorias arquivísticas segundo John Roberts: uma contribuição aos

fundamentos do campo

Palavras chave: Arquivística; arquivos; Arquivologia; arquivistas; fontes de informação.

\section{INTRODUÇÃO}

Após anos de estudo sobre os autores clássicos da Arquivologia como Muller, Feith e Fruin (1940); Jenkinson (1922), Schellenberg (1975) e Duchein (1983), ainda persistiam alguns pontos problemáticos sobre o conceito de fundo, bem como o de princípio da proveniência, impelindo-nos aos seguintes questionamentos: a) será que ainda há necessidade de se estudar e explorar o conceito de fundo e o de princípio da proveniência?; b) o conceito de fundo e o princípio da proveniência realmente diferenciam os documentos de arquivos de outros ?; c) o conceito de fundo e o princípio da proveniência têm o poder de alçar o estudo dos arquivos ao estatuto de uma ciência?

Ao longo de uma pesquisa de doutorado1, levantamos e analisamos extensa bibliografia internacional em que alguns autores questionam tanto o conceito de fundo quanto o princípio da proveniência, enquanto outros reforçam seu papel central e definidor no campo dos estudos dos arquivos. A análise dessa bibliografia nos possibilitou a criação de um quadro sintético, com vistas a facilitar a leitura e a compreensão do leitor sobre as considerações acerca do conceito de fundo e o princípio da proveniência.

Os resultados iniciais daquela pesquisa foram aprofundados em um pósdoutorado $^{2}$ cujo objetivo principal foi verificar a existência da noção de ramificação ${ }^{3}$. Nessa ocasião, foi possível a leitura aprofundada de três textos

\footnotetext{
1 Programa de Pós-graduação em Ciência da Informação da Universidade de Brasília.

2 Programa de Pós-graduação em História Social da Universidade Federal do Estado do Rio de Janeiro - UNIRIO, linha de pesquisa "Cultura, Poder e Representações".

3 "A intercomunicação implícita entre os conjuntos documentais, ou fundos, de instituições distintas, todas envolvidas no cumprimento de uma atividade superior cuja consecução pode extrapolar a missão e as funções de cada instituição separadamente. Essa atividade superior, ou única, que conduz a produção desses documentos, não necessariamente é explícita ou publicada oficialmente". (FRANCO, 2014, p.65). No doutorado demonstramos que essa noção poderia desmitificar os discursos sobre a destruição total dos documentos de arquivo relacionados à Guerrilha do Araguaia.
} 
Shirley Carvalhêdo Franco, Icléia Thiesen, Georgete Medleg Rodrigues

As duas teorias arquivísticas segundo John Roberts: uma contribuição aos fundamentos do campo

do professor norte-americano John Roberts, cujo enfoque seria uma severa crítica a alguns aspectos da teoria arquivística. No sentido de entender melhor o fundamento de suas observações sobre o conceito de fundo e o princípio da proveniência, foram enviadas três perguntas ao referido professor, por correio eletrônico, assim sintetizadas: 1) Are your critical considerations of the Archival theory a product of your theoretical analyses or did you come to those conclusions through practical experience in archives? 2) Your articles suscitated within the archival theoretical field a huge debate among theoretical archivists. Would you be able to elaborate on the possibility that theoretical debate does help to corroborate the existence of an Archival Theory? 3) In the end of one of your articles, it seems as though you were concerned about "the archival profession of the twenty-first century", which you once claimed that it made you "shudder, too, to imagine how little the archival community will be able to contribute when it members are simply well-trained mechanics, steeped in the theoretical frameworks that will enable them to apply nothing more substantial than their informed intuition". Archivists have not only survived, but are also contributing to expand the profession through many actions, such as creating records and archives courses in many universities around the world, publishing thousands articles and books related to the Archival Theory, and helping to elaborate laws. Therefore, is it still your opinion that archivists are still following a path of a "comical archival theory"? Or could it be that we are now closer to a "worthwhile archival theory"?

Traduzidas na íntegra nesse artigo, as respostas de John Roberts, além de apontarem para o que seriam duas teorias arquivísticas - uma, "verdadeira" ou dita "necessária", e a outra, uma "Arquivologia falsa" -, representam um convite irrecusável a uma profunda e contínua reflexão no campo da teoria arquivística, como analisaremos nas próximas seções. 


\section{O CONCEITO DE FUNDO E O PRINCÍPIO DA PROVENIÊNCIA: AUTORES CLÁSSICOS E CONTEMPORÂNEOS}

A partir da leitura e análise dos trabalhos previamente selecionados, conclui-se que as reflexões sobre o conceito de fundo e o de princípio da proveniência podem ser divididas, para fins de análise, em dois grupos: autores clássicos e os autores contemporâneos. Ainda sobre essa categorização, fazse necessário esclarecer que a distinção de um grupo do outro não passa apenas pela questão temporal, sendo determinante, como linha demarcatória entre "clássico" e "contemporâneo", o surgimento e o aumento das críticas ao conceito de fundo e ao princípio da proveniência.

Nas seções subsequentes -- Quadro I e Quadro II--, descreveremos os principais aspectos dos dois grupos, destacando-se, nesses quadros, "ano", "autor", "título e pontos de destaque da obra" e "país de origem do autor".

\section{Quadro I - Autores clássicos}

Os autores clássicos, produtores de obras consideradas como seminais na construção da teoria arquivística, reforçavam tanto o conceito de fundo, quanto o princípio da proveniência como fundamentos do campo.

\begin{tabular}{|c|c|c|c|c|}
\hline & Ano & Título Original & Autor & $\begin{array}{l}\text { País/ } \\
\text { autor }\end{array}$ \\
\hline & 1922 & Manual of Archive Administration. & Hilary Jenkinson & Inglaterra \\
\hline 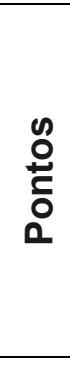 & \multicolumn{4}{|c|}{$\begin{array}{l}\text { O princípio da proveniência e o conceito de fundo são incluídos por Jenkinson } \\
\text { sob a rubrica de defesa moral dos arquivos (moral defense of archives). } \\
\text { Reeditado em } 1937 \text { e 1965, o manual de Jenkinson trata do princípio da } \\
\text { proveniência como "princípio de origem" (principle of origin), ao passo que o } \\
\text { conceito de fundos é denominado "grupo de arquivo" (archive group). } \\
\text { Apresenta, em seu trabalho, de maneira ampla e detalhada, aspectos sobre o } \\
\text { desenvolvimento de ações em torno dos arquivos, sobretudo da Inglaterra, e os } \\
\text { procedimentos adequados para a sua manutenção. }\end{array}$} \\
\hline & 1928 & Archivistica & Eugenio Casanova & Itália \\
\hline$\stackrel{\text { : }}{\stackrel{2}{ \pm}}$ & \multicolumn{4}{|c|}{$\begin{array}{l}\text { Para Casanova, o respeito aos fundos seria um dos cânones da Arquivologia, } \\
\text { por representar a integralidade, a intangibilidade e a inalterabilidade das séries. }\end{array}$} \\
\hline & 1938 & $\begin{array}{l}\text { Manual for the Arrangement and } \\
\text { Description of Archives }\end{array}$ & $\begin{array}{l}\text { Samuel Muller, Johan } \\
\text { Adriaan Feith e } \\
\text { Robert Fruin }\end{array}$ & Holanda \\
\hline
\end{tabular}




\begin{tabular}{|c|c|c|c|c|}
\hline & \multicolumn{4}{|c|}{$\begin{array}{l}\text { Segundo o trio holandês, os documentos } \\
\text { são produtos de um processo histórico. A } \\
\text { para eles, não pode ser subestimada, pois } \\
\text { além de representar um erro científico e } \\
\text { história da instituição. Antes da public } \\
\text { documentos eram dispostos cronologica }\end{array}$} \\
\hline & & & & \\
\hline & \multicolumn{4}{|c|}{$\begin{array}{l}\text { hellenberg atribui valor aos documentos de arquivo seguindo o uso pelo seu } \\
\text { ador nos seguintes termos: valor primário e valor secundário. Primário seria o } \\
\text { or referente ao uso "administrativo, legal e fiscal" exercido e atribuído pela } \\
\text { pria instituição que criou o documento. Quanto ao valor secundário, aqueles } \\
\text { cumentos seriam preservados "como evidência de uma organização ou de } \\
\text { u desenvolvimento funcional, social, econômico ou de outra informação". O } \\
\text { tor estabeleceu, ainda, que o valor secundário poderia ser separado em dois } \\
\text { tros: o valor evidencial, como a evidência presente nos documentos públicos, } \\
\text { erente ao funcionamento e à organização do órgão governamental que os } \\
\text { duziu; e o valor informacional, que seriam as informações contidas nos } \\
\text { cumentos referentes a pessoas, órgãos sociais, problemas, condições e } \\
\text { nelhantes, com as quais o órgão governamental lida. }\end{array}$} \\
\hline & & & & \\
\hline & \multicolumn{4}{|c|}{ rica na ciência arquivística. } \\
\hline
\end{tabular}

Fonte: elaboração própria.

No final da década de 1960 e, como consequência da explosão informacional, produto das duas grandes guerras e das subsequentes transformações tecnológicas, torna-se complexo não apenas o tratamento documental, mas também o entendimento de uma fonte em relação ao seu tempo e espaço. Sendo o documento objeto maior da Arquivologia, seria impossível esse campo passar incólume pelas reflexões e questionamentos de 
Shirley Carvalhêdo Franco, Icléia Thiesen, Georgete Medleg Rodrigues

As duas teorias arquivísticas segundo John Roberts: uma contribuição aos fundamentos do campo

paradigmas.

\section{QUADRO II - Autores Contemporâneos}

Os autores contemporâneos apontam críticas, problemas e questionamentos sobre a prática de tratamento dos documentos tendo como espinha dorsal o conceito de fundo e o princípio da proveniência. Alguns desses autores chegam a apresentar a própria anulação do conceito de fundo enquanto prática e a propor reformulações radicais quanto ao princípio da proveniência, de certa forma abalando a visão geral do que deveria ser considerado enquanto fundamento arquivístico.

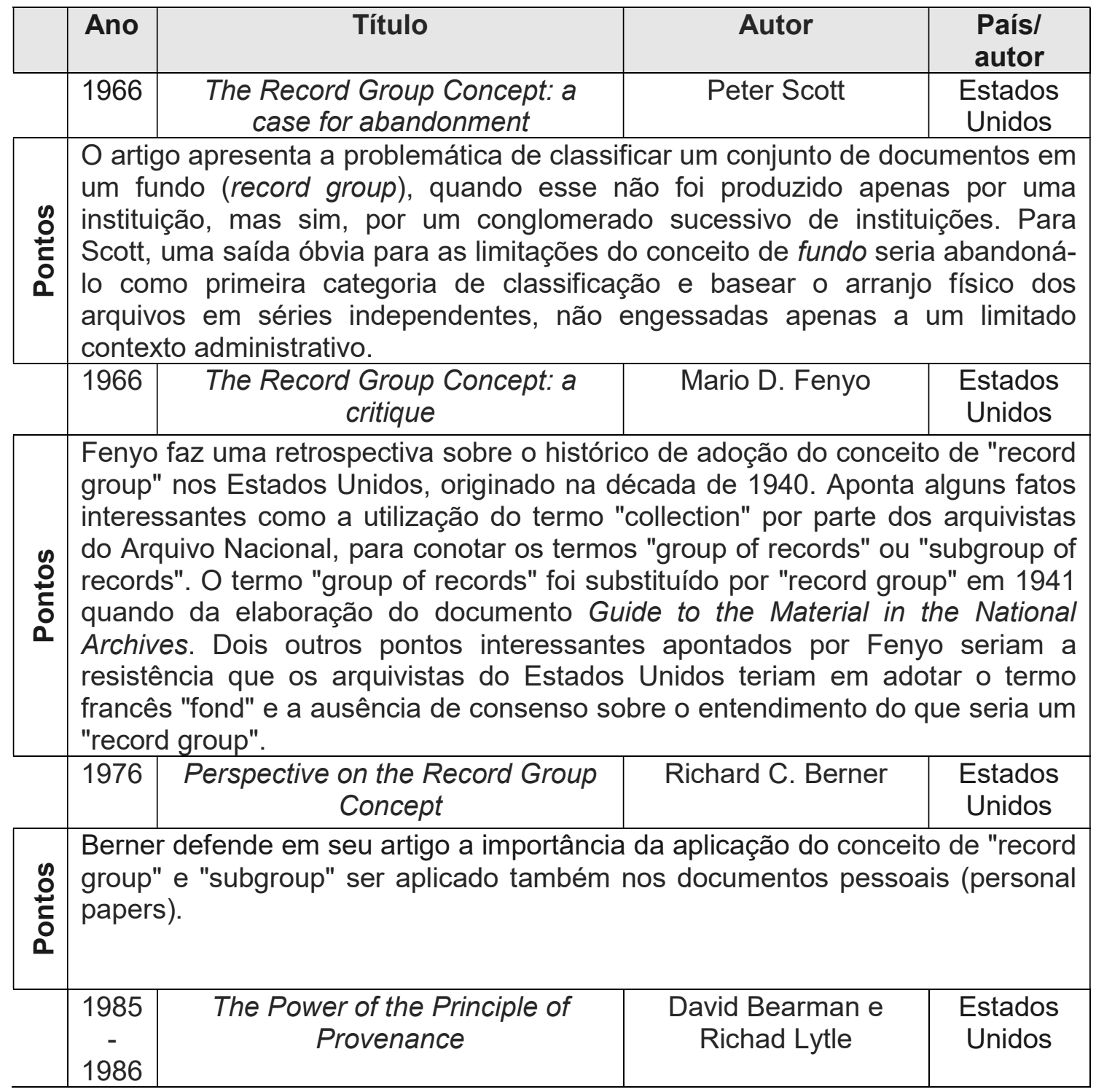




\begin{tabular}{|l|l|l|}
\hline & \multicolumn{1}{l}{ A expansão do princípio da proveniência ou método "P", termo adotado pelos } \\
autores, tem início no entendimento e adoção do modelo de organização \\
contemporânea, ao invés daquele modelo clássico. Para a dupla, os arquivistas \\
ainda encaram as organizações sob aquele molde do século XIX, quando esse \\
princípio foi desenvolvido. Segundo Bearman e Lytle, a insistência de uma \\
prática arquivística orientada com base em organização clássica, como \\
praticavam os norte-americanos ao aplicarem o "record group", ocasiona \\
distorções e disfunções na teoria arquivística. Umas das disfunções seria a \\
confusão em equiparar o princípio da proveniência com a prática do "record \\
group", desconsiderando as suas sérias limitações. Para a dupla, esse conceito \\
tem debilitado a teoria arquivística e limitado, a exemplo dos Estados Unidos, o \\
desenvolvimento efetivo da recuperação de informação baseada na \\
proveniência. Primeiro porque o conceito de "record group" estaria ligado \\
diretamente a uma noção de mono-hierarquia, e em segundo, porque traduz-se \\
em sistema de informação simplista.
\end{tabular}




\begin{tabular}{|c|c|c|c|c|}
\hline & \multicolumn{4}{|c|}{$\begin{array}{l}\text { Para Roberts a teoria arquivística deveria ser verificada de forma a aprofundar o } \\
\text { conhecimento que os arquivistas têm sobre a criação, coleta e gestão dos } \\
\text { arquivos, tendo em vista que, ainda segundo o autor, essa teoria é amplamente } \\
\text { irrelevante para o trabalho arquivístico, promovendo uma divisão indesejada } \\
\text { dentro da profissão, tornando-se, para tanto, intelectualmente inútil. Segundo } \\
\text { Roberts, atrelado à essa inutilidade estaria o fato da teoria arquivística } \\
\text { simplificar aquilo que é complicado, e complicar aquilo que é simples. Complica } \\
\text { ao alçar ao nível filosófico os procedimentos do trabalho arquivístico. Simplifica } \\
\text { por tentar reduzir a fórmulas, fluxogramas e esquemas o conhecimento da área } \\
\text { com o conhecimento de outros tópicos. Sobre avaliação, Roberts afirma que } \\
\text { seria um processo cientificamente falho tendo em vista que a decisão sobre a } \\
\text { conservação da informação estaria atrelada a um julgamento subjetivo. Por fim, } \\
\text { o autor destaca que a teoria arquivística falha em não se centrar no "cenário } \\
\text { maior" do que seria importante na área, levando os arquivistas a se centrarem } \\
\text { mais naquilo que fazem do que naquilo que conhecem, causando uma } \\
\text { "estrutura doentia" na profissão. }\end{array}$} \\
\hline & 1993 & $\begin{array}{c}\text { Archives from the Bottom Up: } \\
\text { Social History and Archival } \\
\text { Scholarship (Canadian archival } \\
\text { studies and the rediscovery of } \\
\text { provenance.) }\end{array}$ & Tom Nesmith & Canadá \\
\hline & \multicolumn{4}{|c|}{$\begin{array}{l}\text { Nesmith discorre sobre como a redescoberta do princípio da proveniência se } \\
\text { tornou paradigmática para a disciplina arquivística e não poderia ser ignorada } \\
\text { por seus praticantes. O autor argumenta que muitos arquivistas ao estudarem } \\
\text { os arquivos e realizarem suas atividades diárias ainda não atribuem ao princípio } \\
\text { da proveniência a importância que lhe é devida. Limitam suas buscas a } \\
\text { informações referentes a datas, nomes e assuntos, deixando, dessa forma } \\
\text { deixando de adquirir o conhecimento advindo do estudo da proveniência e das } \\
\text { questões relacionadas ao contexto, a evolução e o inter-relacionamento dos } \\
\text { documentos arquivísticos. }\end{array}$} \\
\hline & & $\begin{array}{c}\text { The Odyssey of Records } \\
\text { Managers. (Canadian archival } \\
\text { studies and the rediscovery of } \\
\text { provenance.) }\end{array}$ & Luciana Duranti & \\
\hline & \multicolumn{4}{|c|}{$\begin{array}{l}\text { Coautora do mencionado compêndio canadense, Duranti acredita que a nova } \\
\text { percepção sobre a natureza dos documentos arquivísticos e sobre os seus } \\
\text { criadores levará os arquivistas a redescobrirem a sua própria tradição. }\end{array}$} \\
\hline & 1994 & $\begin{array}{l}\text { A Debate on the Validity of Archiva } \\
\text { Theory (Between the Rock and a } \\
\text { Hard Place: archival Theory and }\end{array}$ & John W. Roberts & \\
\hline
\end{tabular}




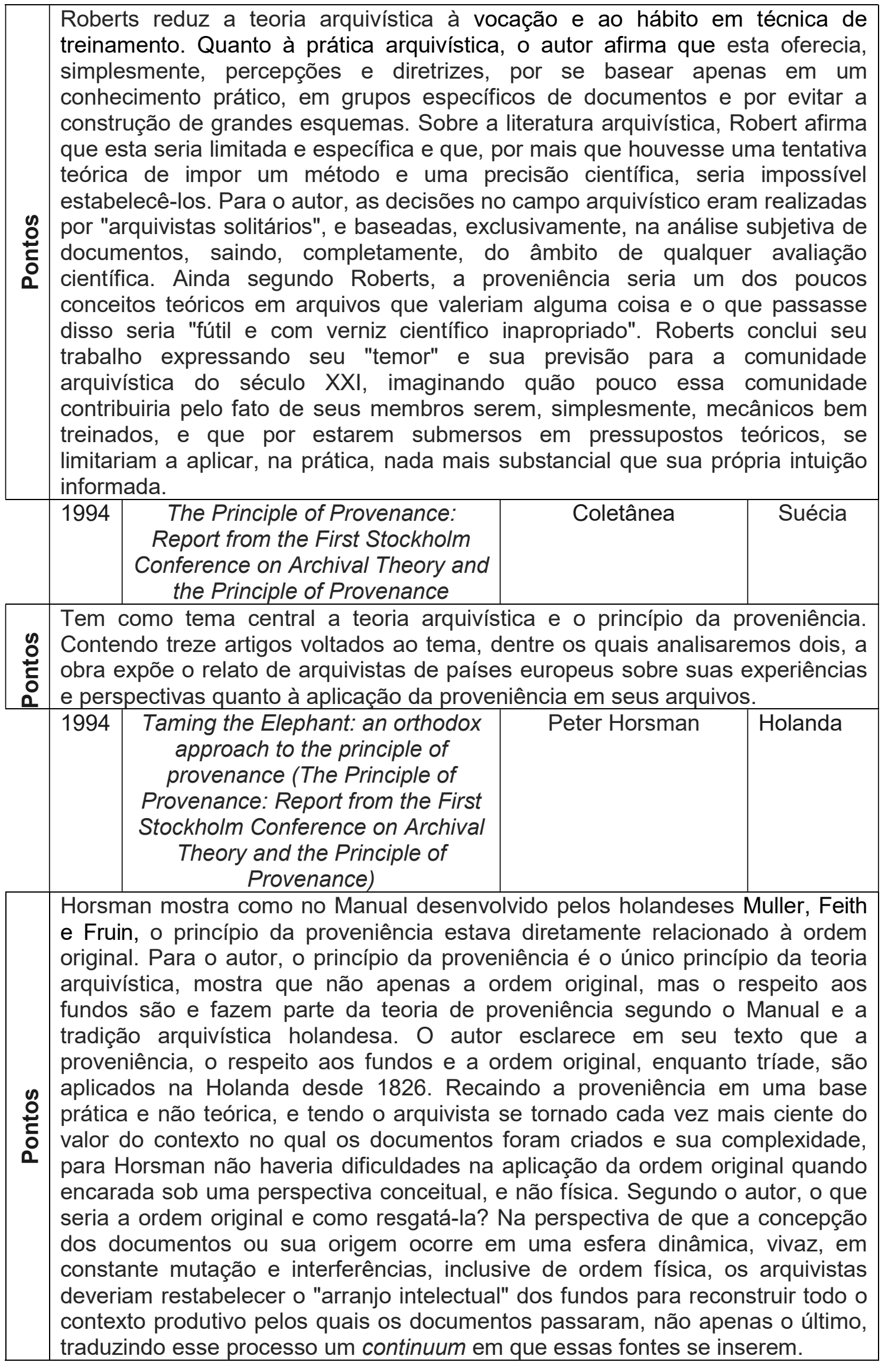


Shirley Carvalhêdo Franco, Icléia Thiesen, Georgete Medleg Rodrigues

As duas teorias arquivísticas segundo John Roberts: uma contribuição aos fundamentos do campo

\begin{tabular}{|l|l|l|c|c|}
\hline 1994 & $\begin{array}{c}\text { Appraisal or Selection? (The } \\
\text { Principle of Provenance: Report } \\
\text { from the First Stockholm } \\
\text { Conference on Archival Theory and } \\
\text { the Principle of Provenance) }\end{array}$ & $\begin{array}{c}\text { Angelika Menne- } \\
\text { Haritz }\end{array}$ & Alemanha \\
\hline & $\begin{array}{l}\text { A autora relata que os Estados Unidos sofreram uma forte influência alemã no } \\
\text { que diz respeito ao princípio da proveniência para avaliação. Parte dessa } \\
\text { influência é atribuída a Ernest Posner que, aos } 46 \text { anos, em 1938, emigrou para } \\
\text { aquele país, sendo, já naquela época, dono de uma grande bagagem } \\
\text { intelectual, por ter sido diretor do Arquivo do Estado da Prússia. Sobre as } \\
\text { funções arquivísticas relacionadas ao princípio da proveniência, Menne-Haritz } \\
\text { assume que os arquivistas deveriam ter uma postura mais ativa no processo de } \\
\text { criação, avaliação e seleção dos documentos. A autora defende que a avaliação } \\
\text { é, provavelmente, a atividade arquivística mais importante e que, dentro dessa } \\
\text { esfera, a evidência é uma meta e não, apenas, uma ferramenta dentro do } \\
\text { processo avaliativo. Defende que os documentos não foram criados para a } \\
\text { "posteridade", mas, sim, para fins administrativos e jurídicos. A autora } \\
\text { demonstra como a avaliação pode e deve ser harmonizada com o princípio da } \\
\text { proveniência e que, sendo a proveniência mais que um princípio organizacional, } \\
\text { deve ser considerada um princípio de arranjo ou de pesquisa. }\end{array}$ \\
\hline $\begin{array}{l}1994 \\
\text { What is Archival Theory and Why } \\
\text { is it Important? }\end{array}$ & \multicolumn{1}{|c|}{ Terry Eastwood } & Canadá \\
\hline
\end{tabular}




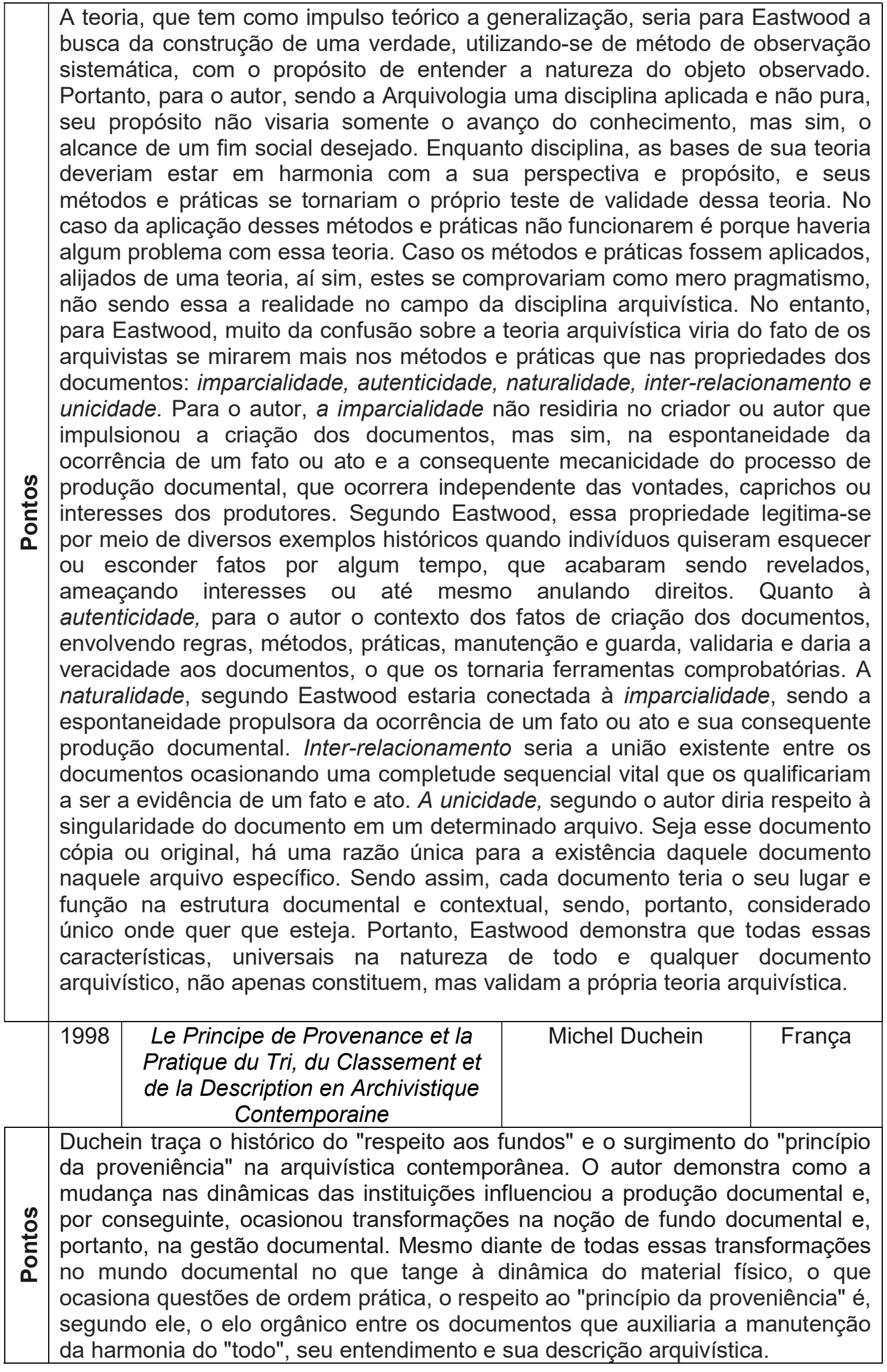


Shirley Carvalhêdo Franco, Icléia Thiesen, Georgete Medleg Rodrigues

As duas teorias arquivísticas segundo John Roberts: uma contribuição aos

fundamentos do campo

\begin{tabular}{|c|c|c|c|c|}
\hline & 2002 & & reter Horsman & \\
\hline & \multicolumn{4}{|c|}{ 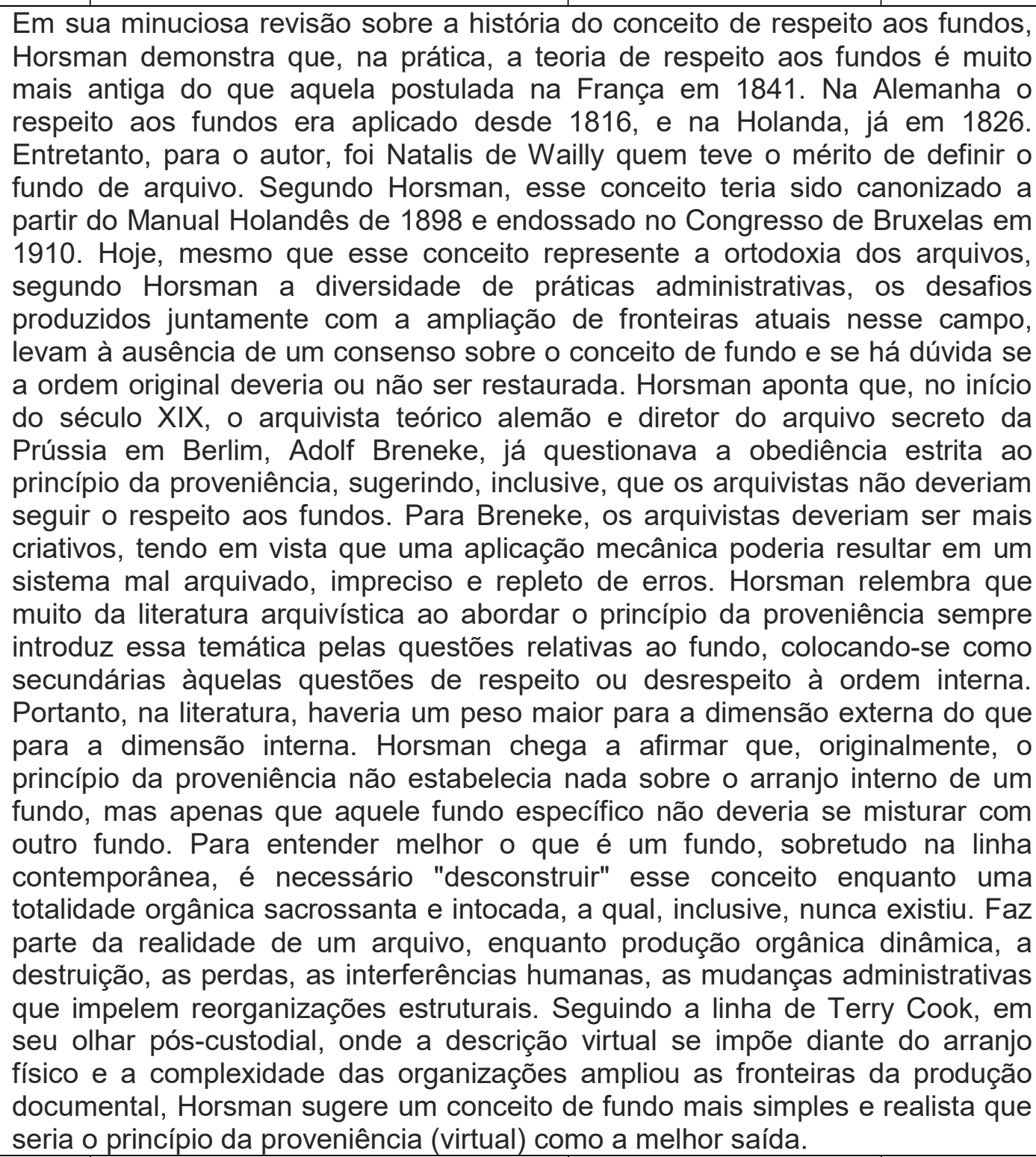 } \\
\hline & & & & \\
\hline
\end{tabular}




\begin{tabular}{|c|c|c|c|c|}
\hline $\begin{array}{l}\text { o } \\
\text { ț } \\
\text { ○े }\end{array}$ & \multicolumn{4}{|c|}{$\begin{array}{l}\text { Numa linha mais radical, a autora propõe o abandono do conceito de fundo } \\
\text { diante da impossibilidade de sua existência no passado, presente ou futuro. } \\
\text { Para ela, o fundo implica uma plenitude, uma completude, uma totalidade. } \\
\text { Argumenta que nenhum arquivo tem, terá ou já teve "a totalidade dos } \\
\text { documentos" de qualquer criador. Documentos são destruídos, perdidos, } \\
\text { transferidos, ou modificados antes mesmo de chegar aos arquivos. Uma vez em } \\
\text { custódia, os documentos podem ser escolhidos, selecionados ou removidos. Os } \\
\text { arquivistas não apenas gerenciam os documentos; eles decidem, ativamente, o } \\
\text { que será mantido e o que será eliminado, por meio do processo de avaliação. } \\
\text { Os arquivistas gerenciam o resíduo, e não a totalidade; a parte, e não a soma. } \\
\text { Com base em experiências nos arquivos canadenses e utilizando-se do } \\
\text { conceito de proveniência existente tanto na Museologia quanto na Antropologia, } \\
\text { Millar sugere que o respeito à proveniência englobaria três elementos: história } \\
\text { do criador, a história dos documentos e a história arquivística. Essa tríade } \\
\text { possibilitaria aos arquivistas fornecerem uma interpretação mais ampla do } \\
\text { contexto no qual os documentos se inserem, por enriquecer a descrição dos } \\
\text { documentos, e além disso, auxiliaria no processo de transparência quanto à } \\
\text { gestão documental. }\end{array}$} \\
\hline & 2010 & & Jennifer Douglas & Canadá \\
\hline
\end{tabular}


Douglas parte da premissa de que o princípio de respeito aos fundos foi desenvolvido antes do princípio da ordem original. Sobre a utilização da "proveniência", menciona alguns autores, como Horsman, que insistem em afirmar que a proveniência não foi uma invenção francesa e que mesmo antes do estabelecimento desse princípio por instrução normativa, no próprio arquivo nacional francês, Armand-Gaston Camus e Pierre-Claude François Daunou já utilizavam uma técnica similar à divisão por fundo. Mais adiante, em 1839, François Guizot, conforme Douglas explica em seu artigo, avançou bastante quando estabeleceu regulações organizando fisicamente os documentos por departamentos. Posteriormente, em 24 de abril de 1841, essas regulações foram reelaboradas por Duchatel sob o título de Instructions pour la mise en ordre et le classement des archives départamentales et communales (a classificação dos arquivos departamentais e municipais) e, nesse mesmo ano, em 8 de junho, Natalis de Wailly elaborou-as em um formato definitivo, posicionando os fundos como ponto focal da organização física dos documentos arquivísticos. No entanto, explica Douglas, também nos arquivos da Prússia, em julho de 1881, Heirinch von Sybel, diretor dos arquivos privados do estado, por meio das regulações Regulative für die Ordnungsarbeiten im Geheimen Staatsarchiv delineadas por Max Lehman, estipulavam a Provenienzprinzip (os documentos de uma administração devem permanecer separados de outra administração distinta) e a Registraturprinzip (a ordem dos documentos deve permanecer na ordem que encontravam em sua administração produtora). Douglas reafirma que a ideia do arquivo enquanto um organismo vivo surgiu no Manual produzido por Feith, Fruin e Muller produzido em 1898, o qual foi traduzido para o alemão em 1905, italiano em 1908 e francês em 1910, e a primeira tradução para o Inglês, segundo o autor, não teria surgido antes de 1940. Sobre a proveniência enquanto um constructo físico e intelectual, Douglas relata que a definição de proveniência foi empregada por Muller em Bruxelas, em 1910, no Congresso Internacional dos Arquivos (ICA). Vinte anos depois, no entanto, o arquivista sueco Carl Weilbull que aceitava o princípio de respeito aos fundos já questionava se a ordem original seria a melhor para a melhor organização física para os pesquisadores. Em uma tendência de reconhecimento do conceito de "fundo" em um patamar muito mais abstrato que físico, Douglas aponta canadenses como Debra Barr, Terry Cook, Max Evans, dentre outros, que elevaram o fundo a um "construto intelectual' por considerarem o enfoque nas relações entre os criadores mais importante que a localização física, dando inclusive origem, no Canadá, ao sistema proveniência societal. Esse sistema considera que as mudanças, valores e contextos da sociedade afetam diretamente a produção documental, tendo, portanto, análise desses aspectos como primazia. Em sua conclusão, Douglas resume em três momentos as mudanças ocorridas no entendimento e aplicação do princípio de origem dos documentos ou proveniência. No primeiro momento, a proveniência foi adotada como um método prático; no segundo, na metade e final do século $X X$, teria surgido uma necessidade de expansão do conceito, o qual deixou de abarcar apenas a linha física, extrapolando a esfera intelectual; no terceiro e último período, o atual, segundo Douglas os arquivistas teóricos, impelidos pelas transformações sofridas na sociedade no que se refere à complexidade administrativa, expandiram o conceito de proveniência em decorrência de este estar intrincado no contexto sociohistórico.

\begin{tabular}{|c|c|c|c|}
2013 & $\begin{array}{c}\text { Disrespect des Fonds: rethinking } \\
\text { arrangement and description in } \\
\text { born-digital archives }\end{array}$ & Jefferson Bailey & $\begin{array}{c}\text { Estados } \\
\text { Unidos }\end{array}$ \\
\hline
\end{tabular}


Shirley Carvalhêdo Franco, Icléia Thiesen, Georgete Medleg Rodrigues

As duas teorias arquivísticas segundo John Roberts: uma contribuição aos

fundamentos do campo

\begin{tabular}{|c|c|c|c|c|}
\hline & \multicolumn{4}{|c|}{$\begin{array}{l}\text { Além de descrever uma retrospectiva crítica sobre o conceito de "fundo", } \\
\text { "princípio da proveniência" e "ordem original", Bailey busca mostrar em seu } \\
\text { artigo a necessidade da emergência de novos modelos teóricos devido às } \\
\text { limitações que permeiam os conceitos "antigos", sobretudo frente aos arquivos } \\
\text { nascidos digitalmente. }\end{array}$} \\
\hline & 2015 & & Shirley Franco & Brasil \\
\hline & \multicolumn{4}{|c|}{$\begin{array}{l}\text { Em seu artigo, a autora apresenta a noção d } \\
\text { impossibilidade da destruição total dos doc } \\
\text { um evento histórico. Franco argumenta } \\
\text { relacionados ao movimento político armado } \\
\text { conhecido como Guerrilha do Araguaia, ainda } \\
\text { exceção não poderiam ter sido destruídos } \\
\text { Regime Militar no Brasil (1964-1985), apes } \\
\text { militares e autoridades oficiais brasileiras } \\
\text { documentos. A própria autora localizou diver } \\
\text { evento em instituições do governo que fize } \\
\text { Guerrilha. Tendo em vista que tanto o conce } \\
\text { da proveniência não foram suficientes par } \\
\text { corpo documental, fez-se necessário trazer à } \\
\text { explicar a sobrevivência daqueles document } \\
\text { ou a inter-relação entre duas ou mais ins } \\
\text { atividade para além do escopo de suas mis } \\
\text { inúmeras tentativas de destruição desse corp }\end{array}$} \\
\hline
\end{tabular}

Fonte: elaboração própria.

De maneira universal, o princípio da proveniência ainda se configura, conforme demonstram os autores supracitados, como conceito fundamental para a arquivística, como também é o conceito de fundo, porquanto ambos representam, segundo eles, a própria essência do documento arquivístico e revelam o fluxo dos documentos. No entanto, a partir da década de 1960, alguns autores iniciam severas críticas ao conceito de fundo no que diz respeito a sua limitação em uma aplicação prática, devido ao surgimento de novos paradigmas e inovações tecnológicas que afetam o campo da Arquivologia, tornando a gênese documental exponencialmente dinâmica e de controle quase inviável.

No bojo dos autores que se dedicaram a analisar criticamente o conceito de "fundo" e o princípio da proveniência, os três artigos do professor norte-americano, John Roberts, produzidos na década de 1990, destacam-se, em grande medida, devido à intensidade de sua posição em relação à Teoria 
arquivística produzida nos últimos anos. No sentido de entender melhor $\mathrm{o}$ fundamento de suas críticas, resolvemos contatá-lo. Via correio eletrônico, enviamos ao autor três perguntas, reproduzidas na íntegra na seção seguinte juntamente com as suas respostas.

\section{CRÍTICAS À TEORIA ARQUIVÍSTICA SOB O OLHAR DE JOHN ROBERTS}

Seus artigos suscitaram, dentro do campo teórico, um grande debate entre os arquivistas. $O$ senhor poderia expor como esse debate auxiliou a comprovar a existência de uma teoria arquivística?

John Roberts: Para responder à sua segunda pergunta, primeiro, eu não acredito que eu já tenha dito que não existia a teoria arquivística - e se eu fiz, então falei errado, porque eu nunca acreditei que a teoria arquivística não existisse. Em vez disso, tentei fazer a distinção entre dois tipos de teoria arquivística. Ambas, certamente, existem, mas apenas uma delas deve existir.

O primeiro tipo de teoria arquivística possibilita um quadro crítico para a formação de um trabalho arquivístico, sendo essa tanto intelectualmente rigorosa quanto absolutamente necessária para o sucesso da gestão de arquivos. Esse tipo de teoria arquivística estabelece os princípios básicos da arquivística: origem, organização hierárquica e ordem original, bem como os valores de avaliação padrão (valor evidencial; valor informativo; valor jurídico; e valor intrínseco). Todos os arquivistas devem entender esses princípios e serem capazes de implementá-los.

Não é exagero destacar a importância destes princípios unificadores. Sem eles, seríamos amaldiçoados com o caos no arquivo: múltiplas nevascas de materiais desconexos e pedaços soltos de dados. Seria impossível o trabalho arquivístico sem esses princípios. Além disso, a pesquisa histórica dentro de tais arquivos seria quase sem sentido, e os historiadores não teriam muita sorte tentando trabalhar com os arquivos que não foram mantidos de acordo com a proveniência e organizados hierarquicamente, seria como tentar trabalhar em uma biblioteca onde todas as páginas de todos os livros tivessem sido rasgadas e organizadas de acordo com os caprichos do momento. 
Shirley Carvalhêdo Franco, Icléia Thiesen, Georgete Medleg Rodrigues

As duas teorias arquivísticas segundo John Roberts: uma contribuição aos fundamentos do campo

Quando ensino da Arquivologia, foco nos princípios, acima de tudo. Quando administro os arquivos, nunca me desvio deles. Este tipo de teoria arquivística é certa, boa e é necessária. Nunca a denegri.

O primeiro tipo de teoria arquivística englobaria também a literatura de "como fazer" - o que explica os padrões de processamento, preservação, descrição e referência; incluindo as minúcias da tabela de temporalidade, variando as técnicas de preservação para diferentes formatos de documentos, elementos dos instrumentos de pesquisa; e assim por diante. Longe de ser um crítico desses princípios arquivísticos tradicionais e da literatura sobre "como fazer" (técnica), sou um mestre nesses tópicos.

O problema, se houver, é que uma vez que esse primeiro tipo de teoria arquivística tenha evoluído, mais ou menos, completamente - dos princípios do Respect des Fonds e dos conceitos de acesso aberto que surgiram na França do século XIX, aos escritos de Muller, Feith e Fruin, e até por Jenkinson, Posner, Holmes, e o melhor do grupo, Schellenberg - não há muito mais a ser dito. Sempre houve espaço para ajustes e aperfeiçoamento. E o surgimento de tecnologias digitais colocou desafios relacionados à tradução de princípios arquivísticos em formatos eletrônicos (um desafio mais prático ou técnico do que propriamente teórico de preservar materiais em formato eletrônico). Mas, uma vez que as bases para o gestão de arquivos foram essencialmente codificadas, há mais de meio século, simplesmente não há muito o que acrescentar. No entanto, isso não impediu as pessoas de tentarem - aí é onde entra o segundo tipo de teoria arquivística.

O segundo tipo de teoria arquivística, oscilando entre o inútil e o tolo, ou mesmo delírio, tenta esboçar o primeiro tipo de teoria arquivística, e indo muito além de um ponto com retorno decadente, ou a conceitos e ideias sequestradas da historiografia, teoria literária, Administração de negócios ou outras disciplinas, para incorporar à teoria arquivística - como se esses conceitos e ideias fossem intrínsecas à teoria arquivística ou pudessem gerar novos "arranques" na teoria arquivística.

Por exemplo, há tentativas de construir sobre os valores básicos de avaliação, módulos elaborados, precisos e pseudocientíficos e sistemas de 
Shirley Carvalhêdo Franco, Icléia Thiesen, Georgete Medleg Rodrigues

As duas teorias arquivísticas segundo John Roberts: uma contribuição aos fundamentos do campo

pontuação que dariam um verniz de objetividade estatística a um processo que ainda depende inteiramente de interpretação subjetiva. E, além disso, esses mecanismos rígidos não acrescentam nada conceitualmente. Os conceitos ainda são exatamente os mesmos, mas os mecanismos tornaram-se desnecessariamente mais complexos, ou a epítome de "mais processo, menos produto", o oposto daquilo que se exige na atualidade que seria "mais produto, menos processo", e com a qual concordo plenamente. Como digo aos meus alunos quando discuto a identificação das hierarquias, "as hierarquias devem ser tão complexas quanto o necessário, mas tão simples quanto o possível". A superelaboração da teoria de avaliação sempre me pareceu introduzir a complexidade por pura complexidade, sem elevar a compreensão ou ofertar quaisquer avanços conceituais.

Depois, há tentativas de incrementar a teoria arquivística baseando-se em outras disciplinas. Até certo ponto, posso ser simpático com os motivos para fazê-lo. Os esforços de F. Gerald $\mathrm{Ham}^{4}$ e outros autores para resolver as lacunas do documento arquivístico, utilizando-se das ideias e interpretações da Escola dos Annales e dos historiadores da nova esquerda dos anos 1960 para a avaliação, temporalidade e políticas de aquisição de acervos arquivísticos foram positivos, admiráveis, muito necessários e completamente justificáveis. Meu argumento não era de ordem prática, seguindo a linha de pensamento de prestigiar aqueles arquivos relacionados a grupos demográficos desfavorecidos: classes trabalhadoras, minorias étnicas e raciais e outras minorias, que, tradicionalmente, foram marginalizadas no registro documental. Pelo contrário, minha objeção era de que essa percepção é produto da pesquisa histórica, não podendo ser identificada a partir de teoria arquivística. A ideia de que uma abordagem teórica arquivística refinada poderia ter evitado tais lacunas, no primeiro momento, e prevenido outras lacunas no porvir, nunca outrora nem mesmo imaginadas, ainda é quimérica. Os arquivistas somente resolveram essas lacunas quando os historiadores reconheceram sua

\footnotetext{
${ }^{4}$ Arquivista norte-americano, autor, dentre outros, de Selecting and Appraising Archives and Manuscripts, publicado pela Society of American Archivist (SAA), em 1993.
} 
Shirley Carvalhêdo Franco, Icléia Thiesen, Georgete Medleg Rodrigues

As duas teorias arquivísticas segundo John Roberts: uma contribuição aos fundamentos do campo

existência, baseados em suas pesquisas e na evolução das escolas de interpretação historiográfica. Não há nada de teórico nisso. É simplesmente o caso de arquivistas aplicarem essas percepções de uma maneira prática em seus esforços de futuras avaliações, e à espera de futuros historiadores terem percepções aprofundadas com semelhantes implicações arquivísticas.

Isso não quer dizer que os arquivistas não poderiam ter essas mesmas percepções por meio de seu trabalho como historiadores. No entanto, esse seria um caso envolvendo arquivistas produzindo pesquisas históricas, ao invés de arquivistas formulando construções teóricas abstratas. Minha própria formação acadêmica é como historiador, e minha carreira tem sido baseada no cruzamento de idas e vindas entre a pesquisa histórica e a gestão de arquivos. Meu trabalho em um campo complementa meu trabalho no outro campo. Mas são dois campos muito distintos e, na minha opinião, é fútil e jocoso tentar enxertar ideias práticas obtidas durante a investigação histórica dentro dos conceitos arquivísticos teóricos. A pesquisa histórica pode avançar as práticas arquivísticas, mas a teoria arquivística vai mais além do que uma mistura requentada de argumentos historiográficos. Ela funciona em uma esfera separada e é igualmente aplicável a todas as escolas de historiografia; a todas as disciplinas acadêmicas e a todos os esforços humanos práticos dentro do governo; na academia; nos negócios; na ciência ou na vida pessoal; onde se gera documentos.

No entanto, sempre fui muito simpático com os esforços para ampliar e aprofundar o documento arquivístico, particularmente, em conexão com grupos sub-documentados. Apenas não vejo isso como algo que possa ser abordado por meio da teoria arquivística. Trata-se, puramente, de um caso de resposta a desenvolvimentos historiográficos.

Tão compreensível quanto a tentativa de incorporar percepções historiográficas na teoria arquivística, são francamente risíveis as muitas tentativas de incorporar ideias de outras disciplinas. Dificilmente, pode-se discutir seriamente, a utilização de teorias weberianas em burocracias, como forma de trampolim para acomodar arquivistas em posições de maior autoridade no governo e nos negócios. Sendo o desconstrutivismo/ pós- 
modernismo tão válido quanto uma teoria literária, e tão na moda (embora completamente fraudulento e mesmo de orientação fascista) como foi um dia a metodologia historiográfica, tentativas de relacioná-los à concepção e gestão de arquivos não devem ser levadas a sério. No momento, estou trabalhando em um artigo científico ou em um capítulo de livro sobre o tema do Desconstrucionismo e teoria arquivística. Oportunamente, entrarei em mais detalhes sobre esse projeto. Mas, por enquanto, considero como intelectualmente falida toda essa abordagem, tendo como exemplo os excessivos contorcionismos daqueles que, nada tendo de melhor a fazer, mas para serem publicados, irão tentar, mesmo que seja sem relevância para a teoria arquivística.

Então, quando você questiona, em sua segunda pergunta, se meus artigos geraram um debate que "corrobora com a existência de uma teoria arquivística", eu responderia que o debate nunca foi sobre a existência de u,a teoria. Ao invés disso, meu argumento tem a ver com quais elementos dessa teoria são válidos e quais elementos são uma piada. Ao longo dos anos, recebi várias cartas de arquivistas do mundo todo, indicando que há, certamente, aqueles que concordam que alguma parte do que começou a se passar por teoria arquivística nos anos 70, e anos posteriores, é, de fato, uma piada.

\section{Suas considerações críticas sobre a teoria arquivística são} produtos de suas análises teóricas ou chegou a essas conclusões por meio de sua experiência prática nos arquivos?

John Roberts: Agora, quanto à sua primeira pergunta, se eu cheguei a minhas conclusões sobre a teoria arquivística por meio de análise teórica ou experiência prática, acho que a resposta seria: "um pouco de ambas".

Como mencionei anteriormente, minha formação acadêmica está na História. Eu ainda era um estudante de pós-graduação quando comecei a trabalhar no Arquivo Nacional e a receber formação em arquivos. Portanto, praticamente ao mesmo tempo em que estudava as escolas de interpretação e metodologia históricas, também iniciava minha experiência prática em arquivos e como isso se relacionava à teoria arquivística. Tudo estava indo bem, até que me deparei com algumas das novas tendências da teoria arquivística. Minha 
Shirley Carvalhêdo Franco, Icléia Thiesen, Georgete Medleg Rodrigues

As duas teorias arquivísticas segundo John Roberts: uma contribuição aos fundamentos do campo

trajetória em História e gestão de arquivos me levou a questionar algumas das mais recentes teorias arquivísticas. Eu estava completamente "por dentro" da tradicional teoria arquivística, mas tendo uma boa base em pensamento crítico, devido ao meu trabalho de pós-graduação, e bom fundamento no trabalho com arquivos, não podia ver como as novas abordagens poderiam passar no teste de riso. Na minha visão, a postura, as reivindicações e a retórica exageradas pareciam uma paródia do discurso acadêmico.

Finalmente, resolvi tomar uma posição depois de ler Frank Burke ${ }^{5}$ "The Future Course of Archival Theory". A comparação de teóricos arquivísticos aos teólogos e dos arquivistas de depósitos aos párocos, deixou-me desiludido. Uma dilatação espantosa da complexidade e importância do papel do teórico arquivístico, comparar teóricos de arquivos aos teólogos e, nesse contexto, condescendendo totalmente em despedir arquivistas de depósitos, como aqueles párocos que precisavam ser liderados por teólogos de bolso. Em última análise, simplesmente, não podia aceitar a noção de que o trabalho com os arquivos era tão difícil que exigia uma elite de teólogos para liderar os exércitos de párocos. Para mim, era emblemática a ideia de Frank sobre um grupo com um complexo de inferioridade profundamente arraigado, tentando ter ares de esperança, mas desesperado para ser aceito como uma verdadeira disciplina acadêmica. ( $\mathrm{Na}$ mesma época, aliás, creio que a Sociedade Americana de Arquivistas não foi aceita como membro do American Council of Learned Societies. Devo acrescentar que a Sociedade Americana de Arquivistas espera, até hoje, por esse convite!).

Ironicamente, tinha um grande respeito por Frank Burke, e ainda tenho. Ele foi arquivista dos Estados Unidos quando estava terminando meu treinamento em gestão de arquivo no Arquivo Nacional, e, na conclusão das aulas do meu treinamento, participei de seu seminário - onde escrevi minha tese, posteriormente publicada como " Archival Theory: Much Ado About Shelving". Embora nesse artigo tenha sido bastante crítico sobre o trabalho de

5 Frank Gerard Burke (1927-2015), arquivista norte-americano, foi arquivista do National Archives e presidente da SAA de 1991 a 1992. 
Frank em " The Future Course of Archival Theory", ele não apenas instigou-me a apresentar meu artigo em seu seminário, como também a submetê-lo para publicação na revista American Archivist. Muitos anos depois, debati com Frank Burke a respeito da teoria arquivística em uma sessão plenária da Conferência Anual da Sociedade de Arquivistas Americanos.

Nesse debate, Frank falou mais sobre a necessidade de os arquivistas assumirem o controle dos programas de educação arquivística que sobre a teoria arquivística e isso faz uma boa ligação com a minha resposta à sua terceira pergunta sobre a profissão do arquivista no século XXI. Embora não preste muita atenção sobre os programas atuais de formação para os arquivistas, entendo que o medo do Frank dos arquivistas profissionais perderem o domínio sobre os programas de formação está se tornando realidade. O campo da Biblioteconomia e Tecnologia da Informação têm se apropriado, em muitos aspectos, da responsabilidade de formar os arquivistas, em parte devido à confusão da contratação de funcionários, não levando em consideração as diferenças entre Biblioteconomia, Tecnologia da Informação, Gestão de Documentos e Gestão de Arquivos. Muitos dos responsáveis pela tarefa de arquivamento não são realmente arquivistas. (Falo tudo isso ciente de que um de seus campos de estudo é a Ciência da Informação, e espero que você entenda que eu não quero ser desrespeitoso com a Ciência da Informação; quero apenas dizer que a Ciência da Informação é diferente da Arquivologia - como é o meu próprio campo da História).

No final de um dos seus artigos, parece que o senhor estava preocupado com "a profissão dos arquivistas no século XXI", chegando a afirmar que essa preocupação o fazia "tremer" por imaginar "quão pouco a comunidade arquivística contribuiria, uma vez que seus membros são mecânicos, simplesmente bem treinados e mergulhados nos referenciais teóricos que lhes permitam aplicar nada mais substancial do que sua intuição informada". Como os arquivistas não apenas sobreviveram, mas também, estão contribuindo para expandir a profissão por meio de várias ações, tais como: a criação de documentos e campos de trabalho relativos aos arquivos em muitas universidades ao redor do mundo, a 
publicação de milhares de artigos e livros relacionados à teoria arquivística, e auxiliando na elaboração de leis... Ainda é a sua opinião de que os arquivistas ainda estejam seguindo um caminho de uma "teoria cômica de arquivo"? Ou pode ser que agora estejamos mais perto de uma "teoria de arquivo valiosa"?

John Roberts: Apesar da proliferação de artigos e cursos que você menciona, vejo jovens arquivistas que, cada vez menos, conseguem identificar uma hierarquia de maneira eficaz, produzir um instrumento de pesquisa decente ou até mesmo distinguir entre um "produtor de documento" e um "criador de documento". Amigos meus que ainda tentam ensinar o estudo dos arquivos nesse ambiente me dizem que eles se sentem como dinossauros em uma era em que a Teoria arquivística básica está sendo esquecida, mal compreendida, corrompida ou mal aplicada. Da mesma maneira, as abordagens tradicionais da referência arquivística e pesquisa histórica - que eu acredito serem as melhores abordagens - estão se deteriorando em um mundo de palavrórios e automação. Eu atribuo isto não apenas à ascensão de profissões não-arquivistas para posições de proeminência no campo arquivístico, mas também à ascensão de uma teoria arquivística "tola" - que, por sua vez, multiplica a teoria arquivística válida da mesma maneira que "a moeda má expele a boa moeda", nas palavras desse famoso adágio, a Lei de Gresham.

\section{CONCLUSÃO}

Conforme exemplificado nos quadros ulteriores, no que tange à teoria arquivística, podemos classificar dois grupos de autores: clássicos e contemporâneos. Não se limitando apenas a um escopo temporal, essa linha divisória entre os dois grupos foi estabelecida com base nos trabalhos científicos selecionados, sobretudo naqueles oriundos da década de 1960, onde se teve início os questionamentos e críticas ao conceito de fundo e ao princípio da proveniência. 
Shirley Carvalhêdo Franco, Icléia Thiesen, Georgete Medleg Rodrigues

As duas teorias arquivísticas segundo John Roberts: uma contribuição aos fundamentos do campo

Nos cinco trabalhos analisados e organizados como "clássicos", os autores mostram a vitalidade do conceito de fundo e princípio da proveniência para a construção da teoria arquivística. Sendo o fundo a "célula mater" dos documentos, por conter o "código genético" dos documentos, o princípio da proveniência seria o outro fundamento da teoria por conter em sua aplicação teórica a própria preservação da unidade e a cadeia documental orgânica.

No entanto, dentre os dezoito artigos analisados e classificados como integrando a fase "contemporânea", as principais críticas atribuídas ao conceito de fundo seriam quanto à ausência de um entendimento universal desse conceito e à existência de uma tensão profissional sobre a impossibilidade de sua aplicação prática diante das rápidas mudanças na dinâmica da sociedade e, por consequência, na administração. Quanto ao princípio da proveniência, e diante da imposição das mudanças sociais e administrativas, os autores sugerem alterações com o objetivo de torná-lo mais eficiente do ponto de vista da gestão documental contemporânea. Inclusive, dentro da problemática dos documentos sensíveis, propusemos a noção de ramificação com o intuito de explicar a existência de documentos produzidos pela intercomunicação ou interconexão de duas ou mais instituições para cumprir uma missão, a qual foge ao escopo de suas missões específicas, como ocorreu no caso da Guerrilha do Araguaia no Brasil.

Quanto às propostas de reformulação e complemento teóricos referentes ao princípio da proveniência, incluindo nesse grupo a noção de ramificação, conclui-se que a intenção dos autores seria muito mais no sentido de colaborar com o refinamento e ampliação do entendimento da dupla "origem e produção" dos documentos arquivísticos, que apenas pôr em dúvida a validade desse princípio enquanto cerne teórico da ISAD (g). Considerando-se as infinitas possibilidades em matéria de "proveniência" no mundo atual, os autores "contemporâneos", de um modo geral, apontam uma reformulação teórica enquanto demanda da gênese documental, muito mais complexa que quando proposto o princípio da proveniência no século XVIII, podendo raramente ser analisada sob o prisma de um único criador. 
Shirley Carvalhêdo Franco, Icléia Thiesen, Georgete Medleg Rodrigues

As duas teorias arquivísticas segundo John Roberts: uma contribuição aos fundamentos do campo

No entanto, dentre esses autores ditos "contemporâneos", John Roberts destaca-se por apresentar uma crítica às críticas ou propostas de reformulações do conceito de fundo e do princípio da proveniência como se esses questionamentos a esses fundamentos fizessem parte do constructo da teoria arquivística.

Com graduação e doutorado em História, John Roberts relata, em sua resposta, que as suas críticas a essas ditas "teorias arquivísticas", geradas tanto de sua prática, quanto de seus estudos sobre a disciplina arquivística, nunca tiveram a intenção de demonstrar que a teoria arquivística não existia, muito pelo contrário. Sua pretensão era apontar a diferença entre o que ele considera como sendo duas teorias arquivísticas: uma "verdadeira" e outra "falsa".

Para Roberts, a teoria verdadeira seria aquela que se refere ao princípio da proveniência, da ordem original, conceito de fundo, organização hierárquica, valores evidencial, informacional, legal e intrínseco. Sendo a teoria verdadeira, os arquivistas deveriam entendê-la e estarem aptos a implementá-la, tendo em vista que sem esta teoria seria um caos o mundo arquivístico, impossível de trabalhar, enfatiza o autor. Seria impossível realizar uma pesquisa histórica em um arquivo que não seguisse o princípio da proveniência. Inclusive, sobre esta teoria, o autor conclui dizendo que, além de ser a que ele enfatiza quando ensina, é a teoria "certa, boa e necessária e que ele nunca, jamais, a denegriu". Com as mudanças tecnológicas e discussões sobre livre acesso à informação e preservação de documento arquivístico em meio eletrônico, há sempre espaço para polir e refinar esta teoria, a qual não deve ser modificada, uma vez que não há necessidade de acréscimo em nenhum de seus pontos estabelecidos há mais de meio século.

O segundo tipo de teoria, considerada pelo autor como "supérflua, tola e delirante", seria aquela que busca incorporar preceitos da historiografia, teoria literária, gestão de negócios, dentre outras disciplinas, na teoria arquivística, como se estes elementos pudessem alavancar novas introspecções, tornando, inclusive, a prática teórica muita mais complexa que produtiva. Não que o autor 
Shirley Carvalhêdo Franco, Icléia Thiesen, Georgete Medleg Rodrigues

As duas teorias arquivísticas segundo John Roberts: uma contribuição aos fundamentos do campo

não seja a favor das trocas disciplinares, mas é necessário haver nessa troca a consciência dos limites da própria teoria arquivística.

Quanto à perda dos limites da teoria e respondendo a nossa última questão, Roberts demonstra que, apesar da ocorrência, no século XXI, da criação de diversos cursos de Arquivologia, os programas têm perdido a sua identidade teórica ao se imiscuir e acabar se confundindo com a Ciência da Informação, a Biblioteconomia e a Tecnologia da Informação, e até mesmo com a História. Complementa enfatizando que, apesar da grande produção de artigos e livros, ele tem contato com arquivistas que sabem cada vez menos sobre a verdadeira teoria arquivística, pelo fato desta ter sido esquecida, mal interpretada, corrompida e mal aplicada, e ter sido dado lugar àquela teoria falsa ou "tola".

No entanto, sobre essa "teoria falsa" ou "tola", segundo Roberts permanece nossa dúvida: sendo os arquivos fontes primárias, criações que refletem o dinamismo da sociedade em toda a sua complexidade e implicações, e sendo a mudança constante o único paradigma nesse século, uma teoria arquivística "verdadeira" não englobaria as evoluções sociais, incluindo, nesse contexto, os questionamentos e reformulações do conceito de fundo e o princípio da proveniência propostas por especialistas, em diversos países? E, ainda, essas reformulações não reforçam o peso teórico desses fundamentos arquivísticos no campo?

\section{REFERÊNCIAS}

BAILEY, Jefferson. Disrespect des Fonds: Rethinking Arrangement and Description in Born-Digital Archives. Archive Journal 3, summer 2013. Disponível em: $<$ http://www.archivejournal.net/issue/3/archives-remixed/disrespect-des-fondsrethinking-arrangement-and-description-in-born-digital-archives/>. Acesso em: 03 mar. 2014.

BEARMAN, David; LYTLE, Richard. The Power of the Principle of Provenance. Archivaria 21, p. 14-27,Winter 1985-86.

BERNER, Richard C. Perspectives on the Record Group Concept. Georgia Archive 4, $\mathrm{n}^{\circ} 1,1976$.

CASANOVA, Eugenio. Archivistica. Lazzeri: Siena, 1928. 
Shirley Carvalhêdo Franco, Icléia Thiesen, Georgete Medleg Rodrigues

As duas teorias arquivísticas segundo John Roberts: uma contribuição aos

fundamentos do campo

COOK, Terry. From information to knowledge: An intelectual paradigma for archives. In: NESMITH, Tom (Org.). Canadian archival studies and the rediscovery of provenance. Metuchen: Scarecrow Press, 1993.

DUCHEIN, Michel. Le principe de provenance et la pratique du tri, du classement et de la description en archivistique contemporaine. Janus, p. 87-100, 1998.

DUCHEIN, Michel. Le Respect des Fonds en Archivistique: principles théoriques et problèmes pratiques. La Gazette des archives Année. Volume 97, Numéro 1, p. 7196, 1977.

DURANTI, Luciana. The odyssey of records managers. In: NESMITH, Tom (Org.). Canadian archival studies and the rediscovery of provenance. Metuchen: Scarecrow Press, 1993.

DOUGLAS, Jennifer. Origins: evolving Ideas about the principle of provenance: In: EASTWOOD, Terry; MACNEIL, Heather (Org.). Currents of archival thinking. Libraries Unlimited, 2010.

EASTWOOD, Terry. What Is Archival Theory, and Why Is it Important? Archivaria 37 p.122-130, Spring 1994.

EASTWOOD, Terry. A contested realm: The nature of archives and the orientation of archival science. In: EASTWOOD, Terry; MACNEIL, Heather (Org.). Currents of archival thinking. Libraries Unlimited, 2010.

FENYO, Mario D. The Record Group Concept: a critique. American Archivist 29, p. 229-239, 1966.

FRANCO, Shirley Carvalhêdo. O "Mito" da Destruição Total de Documentos: um estudo dos arquivos relacionados à Guerrilha do Araguaia à luz de princípios e noções arquivísticas. Tese (Doutorado em Ciência da Informação). Universidade de Brasília, 2012.

FRANCO, Shirley Carvalhêdo. A Noção de Ramificação: uma proposta possível no cenário paradigmático dos fundamentos arquivísticos. Relatório (Pós-doutorado em História Social). Universidade Federal do Estado do Rio de Janeiro (UNIRIO), 2015.

FRANCO, Shirley. The Notion of Ramification of Archival Documents: The Example of the Fonds Related to the Brazilian Political Movement Araguaia Guerrilla. The American Archivist, Vol. 78, No. 1, p.133-153, Spring/Summer 2015.

HORSMAN, Peter. Taming the Elephant: An Orthodox Approach to the Principle of Provenance, in Swedish National Archives, The Principle of Provenance: Report from the First Stockholm Conference on Archival Theory and the Principle of Provenance, 2-3 September 1993 p. 51-63, Stockholm, 1994.

HORSMAN, Peter. The Last Dance of the Phoenix or The De-Discovery of the Archival Fonds. Archivaria 54, p. 1-23, 2002. 
Shirley Carvalhêdo Franco, Icléia Thiesen, Georgete Medleg Rodrigues

As duas teorias arquivísticas segundo John Roberts: uma contribuição aos

fundamentos do campo

ISAD(G). General international standard archival description: adopted by the Committee on Descriptive Standards. Stockholm, Sweden, September 1999.

JENKINSON, Hilary. A manual of archive administration. Oxford: Clarendon Press, 1922.

MENNE-HARITZ, Angelika. Appraisal or selection. Can a content oriented appraisal be harmonized with the principle of provenance, In: The First Stockholm Conference on Archival Theory and the Principle of Provenance, 2-3 September, 1993.

MILLAR, Laura, The Death of the Fonds and the Resurrection of Provenance: Archival Context in Space and Time. Archivaria 53, p. 1-15, Spring 2002.

MULLER, S.; FEITH, J. A.; FRUIN, R. Manual for the Arrangement and Description of Archives. New York: The H. W. Wilson Company, 1940.

ROBERTS, John. Archival Theory: Much Ado About Shelving. American Archivist 50/1 p. 66-74, Winter 1987.

ROBERTS, John. Archival Theory: Myth or Banality, American Archivist 53, 1990.

ROBERTS, John. Practice Makes Perfect, Theory Makes Theorists, Archivaria 37, p. 111-121, Spring1994.

RODRIGUES, Georgete M.; RABELLO, R. Prova documental: valores diplomáticos e formas de representação. Ibersid (Zaragoza), v. 9, p. 29-35, 2015.

SCHELLENBERG, T. R. Modern archives: Principles and techniques. Chicago: The University of Chicago Press, 1975.

SCOTT, Peter J. The record group concept: a case for abandonment, American Archivist (Vol.29, No.4), p.495-496, October 1966.

THIESEN, Icléia. Documentos "sensíveis": produção, retenção, apropriação. Tendências da Pesquisa Brasileira em Ciência da Informação, v.6, n.1, p.1-15, 2013.

Title

The two Archival Theories by John Roberts: a contribution to the fundamentals of the field.

Abstract
Introduction: review of the literature on archival science fundamentals. Goal: to
present some of the points addressed by authors specialized in records and archival
science as they relate to the "principle of provenance" and to the concept of "fund", and
the problems mentioned by some of these authors, especially the thought of the
American archivist John Roberts. Methodology: analyze of 23 scientific works,
including books and articles, and covering the period between 1922 and 2015.
Results: a concise chart organized by "year", "author", "title of the work" and "country
of origin of the Author", dividing classical and contemporary authors. Conclusion:
classical authors reaffirm the validity of archival foundations, contributing to the
construct of the discipline; conversely, however, contemporary authors criticize the Inf. Inf., Londrina, v. 22, n. 3, p. $35-63$, set../out. 2017. 
Shirley Carvalhêdo Franco, Icléia Thiesen, Georgete Medleg Rodrigues

As duas teorias arquivísticas segundo John Roberts: uma contribuição aos

fundamentos do campo

concept of fund, propose its reformulation, and aim to expand the understanding of the principle of provenance, for example, by proposing the "notion of ramification". Among the contemporary authors, John Roberts, an American professor specialized in Records and Archival Science, produced a set of three texts which criticise consecrated elements of archival theory. Based on his answers to the three questions, he presented the genesis of his ideas and formulated a synthesis of two archival theories denominated as "necessary" and the other "superfluous".

Key words: archival studies. Files. records and archival Science. Archivists. source of information.

\section{Titulo}

Las dos teorías de archivo por John Roberts: una contribución a los fundamentos del campo.

\section{RESUMEN}

Introducción: revisión de los fundamentos archivísticos encontrados en la literatura científica. Objetivo: presentar y discutir los principales puntos abordados por los autores archivísticos sobre el "principio de procedencia" y el concepto de "fondo", y los problemas señalados por algunos de esos autores, con destaque para el pensamiento del archivista norteamericano John Roberts. Metodología: análisis de veintitrés trabajos científicos, entre libros y artículos, fechados entre 1922 y 2015 . Además, se formularon tres preguntas a uno de estos autores. Resultados: cuadro teórico sintético organizado por año, autor, título de la obra y país de origen del autor en el que se separan los autores clásicos de los contemporáneos y se expone la visión de cada uno de ellos. Conclusión: mientras los autores clásicos reafirman la validez de los fundamentos archivísticos, con lo que contribuyen para la construcción de la disciplina, los autores contemporáneos, a partir de 1960, pasan a hacerles críticas, sobre todo al concepto de fondo, y a proponer reformulaciones y complementos al principio de procedencia, como el "concepto de ramificación". Entre los autores contemporáneos se destaca John Roberts, profesor estadounidense de Archivística, por la redacción de tres textos con severas críticas a algunos elementos consagrados de la teoría archivística. Roberts también señala la existencia de dos teorías archivísticas: una definida como necesaria y otra como superflua.

Palabras claves: Estudios archivísticos. Archivos. Registros y ciencia archivística. Archiveros. Fuente de información.

Recebido em: 05.07.2017

Aceito em: 11.12.2017 